\title{
Exploring the role of risk perception in influencing flood losses over time
}

\author{
E. Ridolfi, F. Albrecht \& G. Di Baldassarre
}

To cite this article: E. Ridolfi, F. Albrecht \& G. Di Baldassarre (2020) Exploring the role of risk perception in influencing flood losses over time, Hydrological Sciences Journal, 65:1, 12-20, DOI: 10.1080/02626667.2019.1677907

To link to this article: https://doi.org/10.1080/02626667.2019.1677907

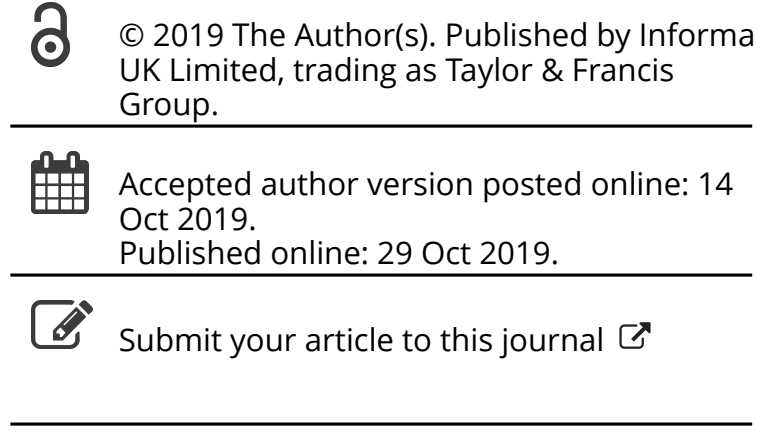

Џll Article views: 352

Q View related articles $\square$

View Crossmark data \lceil 


\title{
Exploring the role of risk perception in influencing flood losses over time
}

\author{
E. Ridolfi $\mathbb{I}^{\mathrm{a}, \mathrm{b}}$, F. Albrecht ${ }^{\mathrm{a}, \mathrm{b}, \mathrm{c}}$ and G. Di Baldassarre ${ }^{\mathrm{a}, \mathrm{b}}$

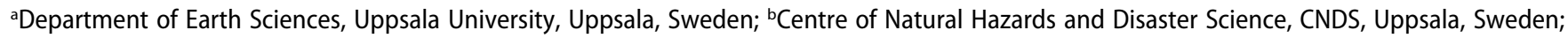 \\ 'Department of Security, Strategy and Leadership, Swedish Defence University, Stockholm, Sweden
}

\begin{abstract}
What implications do societies' risk perceptions have for flood losses? This study uses a stylized, sociohydrological model to simulate the mutual feedbacks between human societies and flood events. It integrates hydrological modelling with cultural theory and proposes four ideal types of society that reflect existing dominant risk perception and management: risk neglecting, risk monitoring, risk downplaying and risk controlling societies. We explore the consequent trajectories of flood risk generated by the interactions between floods and people for these ideal types of society over time. The results suggest that flood losses are substantially reduced when awareness-raising attitudes are promoted through inclusive, participatory approaches in the community. In contrast, societies that rely on top-down hierarchies and structural measures to protect settlements on floodplains may still suffer significant losses during extreme events. This study illustrates how predictions formed through social science theories can be applied and tested in hydrological modelling.
\end{abstract}

\section{ARTICLE HISTORY}

Received 15 March 2019

Accepted 28 August 2019

EDITOR

S. Archfield

GUEST EDITOR

S. Pande

\section{KEYWORDS}

flood risk; socio-hydrology; resilience; risk awareness; cultural theory

\section{Introduction}

Since very ancient times, many human settlements established in close proximity to rivers and their floodplains offer fertile land and easy movement, thereby promoting cultural organization and fostering economic growth (Nardi et al. 2019). Indeed, rivers played a fundamental role in the economic development of societies, as illustrated by ancient major cultures, such as those that settled in Mesopotamia within the Tigris-Euphrates river system. As a matter of fact, nowadays, nine of the 10 largest urban agglomerates in the world are located in deltas or floodplain areas (Di Baldassarre et al. 2013a). However, settling on a floodplain can have catastrophic consequences. The conversion of watersheds into urban areas causes an increase in annual runoff and peak discharge with consequences on the flood volume and thus on the occurrence of flood events (Du et al. 2012, Suriya and Mudgal 2012, Prosdocimi et al. 2015). Scholars attribute the increase in flood-related fatalities to intensive human settlements in flood-prone areas. On the African continent, for instance, the unplanned development of cities has led to settlement in floodplains, which, in turn, has caused an increase in the potential negative consequences of flood events. In the last 50 years, this process resulted in an increase in fatalities of about one order of magnitude in the cities ( $\mathrm{Di}$ Baldassarre et al. 2010).

People respond and adapt to flood risk for different reasons and with varying strategies. Moreover, human actions can greatly alter hydrological extremes through the implementation of control measures. For instance, levee systems and dams affect the frequency and magnitude of floods and droughts (Di Baldassarre et al. 2017). While society changes the hydrological regime and, consequently, hydrological extremes (Viglione et al. 2016); the hydrological extremes, in turn, shape human society.
This paper investigates trajectories of flood risk over time for four types of society that represent ideal types of environmental risk perception and management adapted from Thompson, Ellis and Wildavsky's myths of nature (Thompson et al. 1990). The study applies an extended version of the socio-hydrological model of human-flood interactions (Di Baldassarre et al. 2013b, 2015). Hence, the novelty of this study lies in the integration of hydrological modelling with cultural theory. It is a showcase of how we can utilize and test social scientific theories empirically in hydrological modelling and, therefore, it contributes mutually to social sciences and hydrology.

How can we distinguish between different strategies that societies apply to address flood risk? Empirical research has identified various strategies among societies. Humans respond and adapt to hydrological extremes through soft- and hard-adaptation measures. The former aims at enhancing the awareness of the population at risk, e.g. through community education (Scolobig et al. 2012), early warning systems (Ridolfi et al. 2013, Montesarchio et al. 2014) and change in land-use planning (Raaijmakers et al. 2008). Hard-adaptive measures are constructions, such as levee systems and reservoirs, which reduce the hydrological risk but may fail with catastrophic consequences, e.g. the levee breach in New Orleans, USA, in 2005. When measures increase vulnerability, they can be seen as maladaptive (Barnett and O'Neill 2010, Magnan et al. 2016). Hard-adaptive measures prevent small events and encourage the development in flood-prone areas that are then potentially exposed to large events.

In this study, we assume that preparedness and risk management measures can vary between hard- and soft-adaptive measures. They could also involve risk-avoiding strategies such as resettling (Mård et al. 2018). In doing so, this study takes a societal perspective on preparedness, defined as the 
collective action by the public sector and communities to increase capacities that prepare for and reduce the negative effects of an extreme event. The concept of collective action implies that a group of people, in this case a society, acts together to achieve a common goal that cannot be achieved with individual action alone (Ostrom 2000). This perspective, therefore, does not exclude individual actions and decisions from the concept of preparedness, but it focuses on the societal level and the collective measures when forming theories about societal risk perceptions.

The relationship between risk perceptions and hard-adaptive measures is complicated due to complex effects that hard adaption may cause in society. The levee effect (White 1945) theorizes that flood mitigation structures might increase flood risk, as protection from frequent flooding reduces the risk awareness. Higher levee systems make settlements feel safer and let them engage in the development of floodplains but may fail when extreme events occur, resulting in catastrophic damages.

Flood memory has been shown to have a significant effect on resilience. Long periods of "quiet" can fade the memory that locals built after the occurrence of extreme events (Ullberg 2018). Low levels of flood memory may increase exposure and/ or enable practices that do not cope well with hydrological extremes (Garde-Hansen et al. 2017). The process of forgetting, or even strategically forgetting to cope psychologically with an extreme event, may lead to inadequate response to disasters, as low risk awareness is among the main causes of low preparedness (but not the only one, see e.g. Scolobig et al. 2012). It is important to apply this knowledge in hydrological models to unravel the intertwined relationship between flood risk and societies.

As human society can no longer be considered a boundary condition of the hydrological systems, it is necessary to implement its role in changing water processes, broadening the hydrological science outlook and embracing the perspectives of both social and natural scientists (Sivapalan 2015). Sociohydrology acknowledges the involvement of hydrology in some of the biggest challenges for the Anthropocene. From agent-based models (e.g. Berger et al. 2007, Bakarji et al. 2017) to system dynamics modelling (e.g. Ahmad and Simonovic, 2000, Gohari et al. 2017), the variety of the approaches used to unravel the mutual interaction between society and water systems has proven how this issue has been faced from different perspectives. These approaches have explored diverse types of water systems; for instance, Elshafei et al. (2014) outlined a generic framework for models of socio-hydrology applicable to agricultural catchments; Liu et al. (2014) explored the historical co-evolution of coupled human-water systems in the Tarim River basin and aimed at identifying common patterns supporting socio-hydrological systems. Di Baldassarre et al. (2013a) proposed the application of a socio-hydrological model to uncover the mutual interaction between human societies and floodplain systems. Governance (i.e. the ensemble of principles, rules and procedures which guide the management of a society) affects hydrological processes in floodplains altering the frequency and magnitude of floods, while, in turn, hydrological processes have an impact on the social realm shaping governance processes. Later, several scientists explored the dynamics of flood risk resulting from the interplay between hydrological extremes and societies (Kundzewicz and Kaczmarek 2009, Ciullo et al. 2017, Di Baldassarre et al. 2017). To explore these dynamics, Di Baldassarre et al. (2015) proposed a socio-hydrological model that simulates the co-evolution of population dynamics and flood events on a floodplain. They analyse a hypothetical setting of a city at a river where a community settled, making choices about flood management strategies on the floodplain. Nevertheless, the extraction of information from available data on human and water systems to build socio-hydrological models is not straightforward and it is one of the 23 Unsolved Problems in Hydrology (UPH) identified by the initiative of the International Association of Hydrological Sciences (IAHS) that aims to identify major unsolved scientific problems in hydrology (Blöschl et al. 2019).

The aim of this paper is to gain insights into the influence of risk perceptions on the trajectories of risk generated by human-flood interactions at the timescale of a century and its implication for flood losses. The topic is well placed in the framework of the IAHS Scientific Decade 2013-2022, "Panta Rhei - Everything Flows" (Montanari et al. 2013), which aims to uncover the relationships existing between the water processes and human society.

The analysis is based on an extension of the socio-hydrological model introduced by Di Baldassarre et al. (2013b), whereby the most important feedbacks between the economic, political, technological and hydrological processes characterizing the co-evolution of floods and people are reproduced.

As understanding the differences in environmental risk perception and risk judgements might facilitate the development of effective flood risk mitigation strategies and enhance flood risk communication, we draw upon cultural theory to analyse the interaction between flood events and four ideal types of society. Previous research on landslide risk has reflected on the relevance and implications of different types of society (Scolobig et al. 2017), yet there is no application of these theoretical concepts in socio-hydrological models, which is provided in this study.

\subsection{Risk perception across different cultures}

Cultural dispositions and rationalities stem from different societal backgrounds, which are influenced by the way in which people organize, perceive and justify their social relationships (Scolobig et al. 2017). In turn, these worldviews and value systems are thought to influence risk perceptions, risk judgements and preferences for risk management strategies (Steg and Sievers 2000).

We analyse how four ideal types of society, based on various rationalities rooted in cultural theory, respond to flood risk and what the implications and consequences of their behaviour are. Here, risk rationalities are understood as the fundamental risk perceptions in a society that will decide over actions to prepare for and manage flood risks. Although socio-hydrology aims at investigating human processes and their interaction with water systems in the best possible way, human processes are immeasurably more complex; to quote from Pete Loucks: "There are no laws of social behavior as there 
are for the physics, chemistry, and biology of water and ecology" (Loucks 2015). To deal with this complexity, this study opts for investigating ideal types of society. An ideal type of a society is not a representation of reality, it is an analytical tool used to investigate differences between societies in their purest form. Ideal types have a long tradition in social sciences since the 19th century and Max Weber's work on bureaucracy (Watkins 1952). In this study, we investigate how underlying risk rationalities in ideal types of society shape flood risk perception and management, which may result in varying trajectories of risk and how, in turn, flood events shape these ideal types of society. Thus, ideal types can be used to construct theories, but they can also provide an explanation and interpretation of reality. In the real world, of course, societies naturally consist of mixes of these different rationalities. It would be impossible to identify, let alone analyse all different mixes of rationalities, but the application of ideal types enables an analysis of societies in their purest form and enhances our analytical understanding of societies.

Cultural theory argues that views and behaviours related to some key issues often cluster, i.e. shared, structured ways of speaking, thinking, behaving, perceiving and solving problems (Dryzek 2013). By implication, risks are socially constructed and people choose what and how to fear to sustain their preferred pattern of social relationships (Douglas and Wildavsky 1982). Risks are also socially produced, as they depend on how societies interpret and act on perceived risk (Tierney 2014). Hence, the core of cultural theory in relation to hydrological extremes is to explain the social construction and production of risk through cultural rationalities. In addition, cultural theory aims specifically not only to describe a society but also to predict behaviour that develops based on the attitudes held in a society (Steg and Sievers 2000). By implication, cultural theory in relation to environmental risk uses risk rationalities to construct a framework with ideal types of society in relation to environmental risk. These ideal types of society and their embedded risk rationalities are assumed, accordingly, to cause collective action of societies regarding whether and how to address environmental risks. Therefore, this study investigates the effect of typical behaviour predicted for different ideal types of society on flood losses over time.

Scholars have proposed four rationalities that describe the relationship between societies and nature, also referred to as myths of nature: fatalistic, hierarchical, individualist and egalitarian (Thompson et al. 1990, Steg and Sievers 2000). Developed for general environmental risk, we adopt these ideal types of society and interpret them from a flood-risk perspective to propose four risk rationalities that shape ideal types of society in relation to hydrological extremes. We propose to call them risk neglecting, risk controlling, risk downplaying and risk monitoring societies. Figure 1 illustrates all four rationalities; represented as a ball in an environment. The line symbolizes the perceived vulnerability and the robustness of the system. The ball represents how societies interpret their own position in their built environment determined by their environment-risky behaviour. While all balls are in an equilibrium in their current state, some societies perceive themselves to be in a precarious balance, which could easily be disturbed (e.g. Fig. 1(d)), while others perceive themselves to be in a robust system where more environmental-risky behaviour will hardly have negative consequences (e.g. Fig. 1(c). Thus, the shape of the line and the position of the ball predict how this society estimates whether risk management strategies are necessary, urgent, or not necessary at all. The four rationalities that shape the societies are assumed to inform and predict the society's environment-risky behaviour and actions they may take to address a potentially perceived risk. To explain the nature of these four ideal types of society further, picture a settlement on a floodplain. How is risk perceived and managed in each society?

The risk neglecting (or fatalist, Fig. 1(a)) society sees nature as an unmanageable system. Therefore, there is no need to be concerned or to plan the future. "Risk perception is based on the credence that what you do not know cannot hurt you" (Steg and Sievers 2000). In the context of hydrological extremes, the risk neglecting society does not adopt hard or soft measures for preparedness because it is built on the rationality that it is impossible to manage risks. Hence, preparedness in any form is non-existent. By implication, remembering flood events has no effect on the preparedness of the society either. Accordingly, the population will continue to grow, unrelated to the fact whether the settlement is on a floodplain or not.

The risk controlling (or hierarchical, Fig. 1(b)) society conceives nature as a system that is robust to a certain extent. This society is capable of perceiving risks as such and the need to increase preparedness. Individuals trust the hierarchical organization of society and, by extension, authorities, to take appropriate decisions. The society assumes that needs in the population cannot be adjusted and opts, therefore, to control nature and its risks instead. To do so, this society relies on government regulations with a top-down perspective and expert judgements (Steg and Sievers 2000). Empirically, this has been found to translate to the adoption of technological measures, typically structural, or other hard measures (Scolobig et al. 2017). Therefore, we can also understand this society as a technological society. Once a hard measure (e.g. levee system) has been recommended by experts, implemented and deemed safe by authorities, the population feels safe behind the levees.

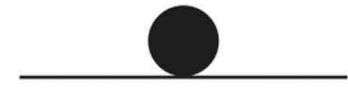

a) Risk neglecting

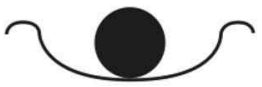

b) Risk controlling

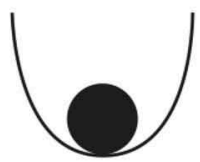

c) Risk downplaying

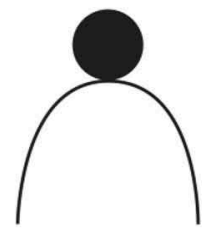

d) Risk monitoring

Figure 1. Representation of the four myths of nature (or rationalities) according to their main features and their view of nature (after Thompson et al. 1990). (a) risk neglecting; (b) risk controlling; (c) risk downplaying and (d) risk monitoring. 
Accordingly, population growth occurs independently from the location of a floodplain if it is protected by hard measures and approved for settlement by authorities. In this society, memories of past floods would prevail for a significant period of time until levees have been constructed that are deemed by experts and governments to protect the society.

The risk downplaying (or individualist, Fig. 1(c)) society perceives nature as a robust system. Environmental risks, including hydrological extremes, are generally downplayed or strongly underestimated. This society does not see any need for collective action. By implication, appropriate soft or hard measures are unlikely to be implemented and the society is not well prepared to face flood risk. Neither will the settlement relocate in case of flood occurrence, i.e. the population will continue to grow in the settlement. The lack of engagement with the matter of flood risks and the underestimation of the society's risk will likely result in floods not remaining on the agenda for a long time. By implication, this society will forget about past events comparatively quickly.

The risk monitoring (or egalitarian, Fig. 1(d)) society is the only society that perceives itself to be in a precarious balance, which could easily be disturbed with catastrophic consequences if risk is not addressed appropriately. In contrast to risk controlling societies, risk monitoring societies assume that natural resources cannot be controlled, while needs can and should be adapted (Steg and Sievers 2000). They encourage risk management strategies that are inclusive and promote equality for all in the present and future. Therefore, adopted measures are generally community-based and inclusive bottom-up strategies that adopt participatory soft measures, e.g. citizen-based early warning systems, resulting in greater awareness and preparedness in the whole society (Scolobig et al. 2017). Since communities understand and are actively involved in their risk assessment, we can assume that their memory of past events will not fade. The realization that it is the population's needs that have to change and not nature will likely also cause relocation of settlements from the floodplain, which implies that population density on floodplains will decrease, or increase substantially less, than in other societies.

\section{Socio-hydrological model}

We are interested in assessing different trajectories of flood risk stemming from four ideal types of society built on cultural rationalities and how, in turn, flood events affect each type of society and what long-term consequences exist in relation to flood losses. To this end, we adopt a socio-hydrological model built on the basis of the one proposed by Di Baldassarre et al. (2015). The model is able to simulate the mutual interaction between hydrological extremes and societal factors.

The model conceptualizes the human-flood interplay representing a community which lives and develops in a flood-prone area. It is based on a lumped conceptualization, which does not account for the spatial variability of the flooding. Thus, the areas are subdivided in floodplain and other areas. The occurrence of a flood event causes damage and may trigger relocation of people or other measures. Time-varying variables are in capital (uppercase) letters; however, the time is not indicated in the equations for the sake of brevity.

The conceptualization assumes the occurrence of a series of peak-over-threshold water level values $(W)$, which have different magnitude and irregular inter-arrival time. The society may, or may not, respond to the flood event by building a levee system to protect the settlement. The height of the levee system existing before the occurrence of the flood is indicated as $H_{-}$. The damage $(F)$ depends on the actual high water level and, thus, it depends on the water level overtopping the levee, if any is built. The value of $F$ varies between 0 and 1 and it is estimated according to the Hydrology equation, as follows:

$$
F=1-\exp \left(-\frac{W+\xi_{H} H_{-}}{\alpha_{H}}\right) \text { if } W+\xi_{H} H_{-}>\mathrm{H}_{-}
$$

where $\xi_{H}$ is the flood level enhancement due to the presence of the levee system (here not considered and set equal to 0 ) and $\alpha_{H}$ is a parameter related to the flood depth-damage curve.

In this paper, we are dealing with four different rationalities that face flood risk in four different ways. However, regarding the management of the floodplain and, specifically, of the protection measures, we can identify two main management systems: (i) societies that fight the floods (e.g. risk controlling) and thus build or raise a levee system; and (ii) societies that neglect or adapt to floods (e.g. risk monitoring) and, therefore, do not build levee systems. The levee heightening $(R)$ is assumed to be proportional to the difference between the actual high water level and the flood protection level:

$$
R=\left\{\begin{array}{cc}
\varepsilon_{T}\left(W-\xi_{H} H_{-}-H_{-}\right) & \text {with levees } \\
0 & \text { no levees }
\end{array}\right.
$$

where $\xi_{T}$ is a safety factor for levee heightening. To simulate the impact of the community on the flood system, Equation (1) is coupled to three differential equations that model the interplay between the flood system and the human system:

$$
\left\{\begin{array}{l}
\frac{\mathrm{d} D}{\mathrm{~d} t}=\rho_{D}\left[1-D\left(1+\alpha_{D} M\right)\right]-\Delta(\psi(t)) \cdot F D_{-} \\
\frac{\mathrm{d} H}{\mathrm{~d} t}=\Delta(\psi(t)) \cdot R-\kappa_{T} H \\
\frac{\mathrm{d} M}{\mathrm{~d} t}=\Delta(\psi(t)) \cdot F \mathrm{D}_{-}-\mu_{S} M
\end{array}\right.
$$

The three differential equations schematize the co-evolution throughout time of population density $(D)$, technology $(H$; i.e. the flood protection level) and society ( $M$; i.e. societal memory of floods), as soon as they are altered by the occurrence of a flood. In Equation (3), $\rho_{D}$ is the population growth, $\alpha_{D}$ is the ratio of preparedness/awareness, $k_{T}$ is the protection level decay rate and $\mu_{S}$ is the memory loss rate. The reduction of the population due to the relocation of people after a flood event and the contemporaneous building of societal memory and the heightening of levees (for the risk controlling societies only) are modelled as instantaneous. This is modelled via the Dirac comb $\Delta(\psi(t))$ that is always zero, except when $\psi(t)=0$ and assumes the value of 1 (i.e. when the flood occurs). Therefore, the terms multiplying the Dirac comb exist only after the occurrence of a flood: - FD_ (flood losses, expressed as sudden reduction of population density), $+R$ (levee heightening), and $+F D_{-}$(accumulation of memory, assumed proportional to flood losses). 
As soon as the community experiences a flood event, it builds memory $(M)$ of the flooding, which is a crucial resource when making decisions on how to manage flood risk. Consequently, people may decide to leave the floodplain and relocate elsewhere, thus the population in the floodplain may decrease $(D$; the population density varies between 0 and 1 , where 0 implies that no population is settled in the floodplain, while 1 means that all the population is settled in the floodplain). As a response to the flood event, the community may also decide to either protect the floodplain with structural measures (i.e. building or heightening levees; $H$ ), or not. As initial conditions, we assume that all variables start from null values. Of course, relocation or building levees are not the only potential reactions to a flood event, but they should be seen as examples of typical measures in different types of society (see more about implemented measures below).

The memory, built because of the occurrence of flooding, reduces to half its initial value in a time (half-life, $\lambda$ ) and it is estimated as:

$$
\mu_{S}=\frac{\ln (2)}{\lambda}
$$

The parameter $\mu_{\mathrm{S}}$ describes the process of learning and forgetting that the community experiences across time. This hypothesis is based on the empirical evidence that risk preparedness is maximum after the occurrence of an event, while it decays over time (Hanak 2011). All parameters involved in the model are described in Table 1.

In the following, we summarize the assumptions for each type of society in the framework of the model conceptualization that will be used to assess the corresponding trajectories of risk.

\subsection{How different societies would face flood risk}

Each type of society faces hydrological risk with different behaviour. To simulate each behaviour and its implication for floodrisk management and its consequences, we implement the model proposed by Di Baldassarre et al. (2015), which simulates the mutual feedback between floods and society. We recall that the behaviour of each type of society is implemented in the model via different factors, which are preparedness, measures taken to face the flood risk, flood memory and population density in the floodplain. In the following sections, we present the description of our assumptions about each factor for the four types of society. Table 2 reports the range of variation of all factors for each type society.

\subsubsection{Preparedness}

The risk neglecting society does not adopt measures of preparedness for floods because it assumes that it is impossible to manage risks. In the socio-hydrological model, the ratio between preparedness and awareness is expressed by the parameter $\alpha_{D}$ (Table 2), which is thus zero for risk neglecting societies. The risk controlling society is characterized by high preparedness, as they are aware of the risk and realize the need to be prepared to face it. Thus, $\alpha_{D}$ ranges between high values. The risk downplaying society believes itself to be in a sound equilibrium. Therefore, it is not well prepared to face flood risk and $\alpha_{D}$ is low. Risk monitoring societies are associated with a higher risk awareness and are more eager to apply policy measures, especially compared to risk downplaying societies (Steg and Sievers 2000). Since the risk monitors take a variety of soft measures that increase their awareness and monitor the risk, they are more prepared than any other society to face flooding and are thus characterized by the highest $\alpha_{D}$.

\subsubsection{Implemented measures}

Hard protection measures are explored separately as the building of levees is the only structural change to the environment that causes a change in exposure up to a certain threshold. Concerning actions taken to protect the settlements against flood events, only the risk controlling society will construct structural or hard protection measures. Risk neglecting and risk downplaying societies do not take any measures, or take inadequate measures, for flood protection for reasons elaborated above. Risk monitoring societies take a different approach to risk management and pursue participatory approaches to monitor risk collectively. This involves the implementation of soft measures that lead to high population

Table 1. Parameters of the socio-hydrological model used in the analysis. The values varying in a range depend on each specific society (see Table 2).

\begin{tabular}{|c|c|c|c|}
\hline Parameter & Description & Value & Notes \\
\hline$a_{H}$ & Related to the flood depth-damage curve & $10 \mathrm{~m}$ & Penning-Rowsell (1996) \\
\hline$\xi_{H}$ & High water level enhancement due to presence of flood walls & 0 & Not considered \\
\hline$\rho_{D}$ & Mean relative growth rate & $0.001-0.08$ years $^{-1}$ & \\
\hline$K_{T}$ & Protection level decay rate & $2 \times 10^{-5}$ year $^{-1}$ & Di Baldassarre et al. (2015) \\
\hline$a_{D}$ & Ratio between preparedness and awareness & $0-15$ & \\
\hline$\xi_{T}$ & Safety factor for flood walls & 1.1 & Da Deppo et al. (2004) \\
\hline$\lambda$ & Years in which the memory reduces to half its initial value & $2-15$ years & \\
\hline
\end{tabular}

Table 2. Parameters of the socio-hydrological model, which vary depending on each ideal type of society.

\begin{tabular}{lcccc}
\hline \multicolumn{4}{c}{ Society } \\
\hline Parameter & $\begin{array}{c}\text { Risk Neglecting } \\
\text { (fatalistic) }\end{array}$ & $\begin{array}{c}\text { Risk Controlling } \\
\text { (hierarchical) }\end{array}$ & $\begin{array}{c}\text { Risk downplaying } \\
\text { (individualist) }\end{array}$ & $\begin{array}{c}\text { Risk monitoring } \\
\text { (egalitarian) }\end{array}$ \\
\hline$a_{D}$ & 0 & $2.5-7.5$ & $0.5-5.5$ & $7.5-15$ \\
$\lambda$ & $2-8$ yrs & $5-10$ yrs & $2-5$ yrs & $5-15$ yrs \\
levee construction & no & yes & no & no \\
$\rho_{D}$ & $0.02-0.08$ yrs $^{-1}$ & $0.02-0.04 \mathrm{yrs}^{-1}$ & $0.02-0.04 \mathrm{yrs}^{-1}$ & $0.001-0.01 \mathrm{yrs}^{-1}$ \\
\hline
\end{tabular}


awareness and may involve re-settling from the floodplains. These soft measures are implemented in the model through the preparedness and population growth variables.

\subsubsection{Memory}

We are interested in how long societies remember floods and what the potential of the flood memory is to inform and change flood governance, i.e. for how many years could flood memory trigger changes in policies or behaviours to manage flood risks. Memory may persist differently long and have different effects on policies and decisions depending on the type of society. For instance, memory does not influence the decision-making process of societies that neglect risks. They do not make decisions based on their memory of floods, i.e. longor short-term; therefore, no matter how much they recall an event occurred in the past, it will not influence their behaviour. For this type of society, we assume that the memory may be any value and thus the factor which considers the memory $(\lambda)$ may vary largely. Risk controlling societies are not bothered by events that did not overwhelm their existing protection measures, but their memory of a flood that overwhelms their protection mechanisms could have long-lasting effects with an impact on policy making, as they may demand a re-evaluation and re-construction of protection measures based on expert advice. Risk downplaying societies' memory may last and have an effect only for a short duration, as they perceive themselves in a robust environment that is only temporally negatively affected by flood risks. Risk monitoring societies' flood memories will likely persist and inform policies for a long time, as they are constantly involved in flood risk management through the implemented participatory approaches, thus $\lambda$ varies between high values.

\subsubsection{Demographic growth}

We interpret demographic growth as a means to measure how the population reacts to flood risks. We assume that the population will naturally grow over time, with the ongoing development of a society without flood interference. The population growth in the floodplain is zero immediately after the occurrence of a flood event and then grows throughout time until the next flood event occurs. The model tracks population reactions in different societies through more or less rapid demographic growth in the area, or through relocation from the floodplain that will halt demographic growth. In a risk neglecting society, the population density in the floodplain may assume any value, because this society does not make settlement decisions based on flood risk. Societies that control risk feel safe as long as they are protected by levees; hence, they would not leave the flood-prone area and, instead, their population will continue to grow in areas deemed safe by authorities (i.e. demographic growth, $\rho_{D}$, is high). Since the population in risk downplaying societies underestimates the hazard, after the occurrence of a flood event, it also grows quickly in the floodplain (i.e. $\rho_{D}$ is high). In contrast, societies that monitor their risk and shape an active memory and understanding of their own status through participatory approaches would create awareness of flood-prone spaces, which could lead to them adopting soft measures, such as avoiding floodplains (i.e. $\rho_{D}$ is low).

\section{Results and discussion}

The results are presented in terms of levee height, social memory, population density in the floodplain and flood losses for each type of society (Fig. 2). They illustrate the ability of the model to reproduce the previously theorized behaviour and estimate the flood damage.

Societies that neglect risks experience all flood events as they lack structural protection measures (Fig. 2(a1)). Flood memory does not affect decisions to live on a floodplain, regardless of how long these societies remember a flood (Fig. 2(a2) and (a3)). Consequently, every flood event causes substantial flood damage of a magnitude that depends on the population density (Fig. 2(a4)).

Risk controlling societies rely on expert judgements, leading them to build levee systems that are increased in height over time (Fig. 2(b1)). As long as the water levels are below the protection level, no major flood losses are recorded. However, when a flood with higher magnitude occurs, damages are high as the flood affects many citizens (Fig. 2(b4)). Events with waterlevel values lower than the levee systems are forgotten quickly by the society. Major events refresh flood memory which then
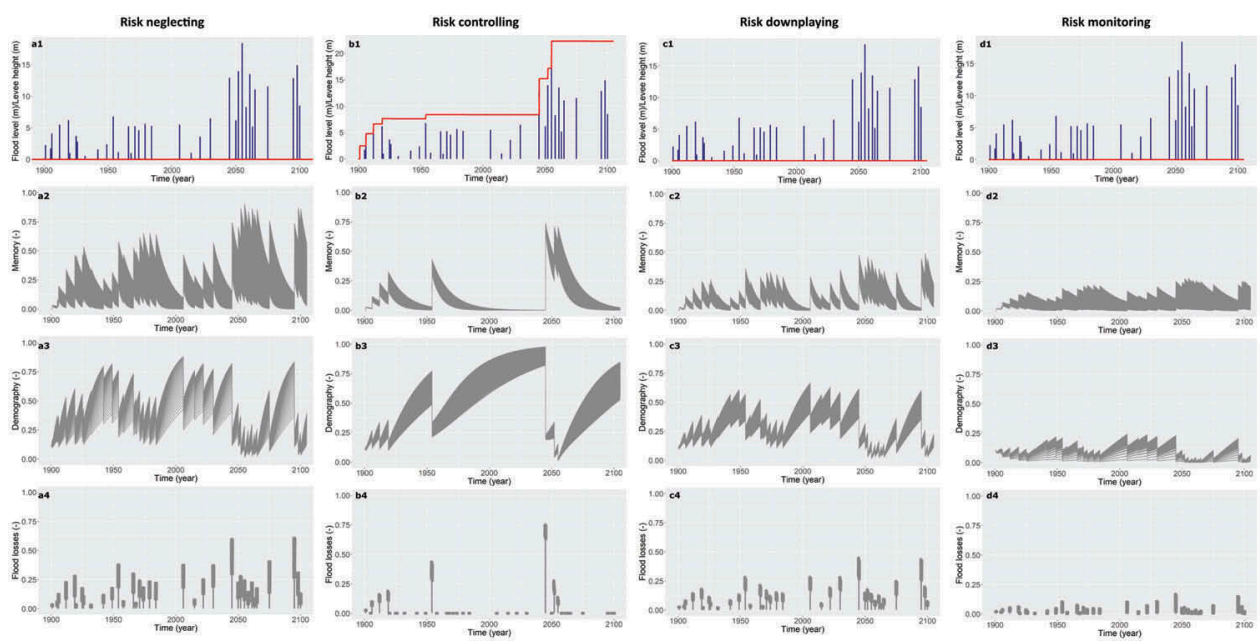

Figure 2. Outcomes of the socio-hydrological model for each stylized society, (a) risk neglecting, (b) risk controlling, (c) risk downplaying and (d) risk monitoring, in terms of (1) levee construction, (2) social memory of flood event, (3) population density in the floodplain and (4) flood losses. 
decreases as long as no flood events are experienced (Fig. 2(b2)). This feeling of safety and lack of flood memory thus encourages undisturbed population growth, the highest compared to the other three societies (Fig. 2(b3)).

Risk downplaying societies feel comparatively safe and refrain from building levees (Fig. 2(c1)). Despite experiencing all flood events, they forget them comparatively quickly (Fig. 2 (c2)). Since the society underestimates risk, settlements remain on floodplains despite flood occurrence (Fig. 2(c3)). The preparedness to face the flood risk is low because of the perception of system robustness. The society's behaviour thus entails high flood damages repeatedly (Fig. 2(c4)).

Societies that focus primarily on risk monitoring do not build levee systems (Fig. 2(d1)) but pursue a participatory approach which raises risk awareness and preparedness. The high level of risk awareness is represented by long-lasting flood memory and a low population density in the floodplain (Fig. 2(d2) and (d3)), as the society acknowledges the necessity of settling further from the river. Decreasing population growth in the floodplain is connected to decreasing flood losses. This adaptive behaviour continuously results in smaller flood losses than in other societies (Fig. 2(d4)). It is worth noting that, for risk monitoring societies, the population density varies in the lowest range compared to the other three communities and, thus, also the upper bounds of flood damages are smaller. This result does not imply that resettling is the only option to reduce flood losses but illustrates that participatory and inclusive measures yield many benefits, as they create highly prepared societies that do not forget existing hazards and change their behaviour if necessary.

The four different rationalities help us to understand the possible risk trajectories outlined by different ways of dealing with flood risk. Moreover, these ideal types of society offer a unique opportunity to compare different behaviours and their effect in terms of losses. Hence, the results show how theoretical assumptions formed through cultural theory translate into actual numbers and estimates of flood losses over time. The mutual feedback between flood events and societies is well represented by the socio-hydrological model and helps us to understand how this loop further develops throughout time. Ignoring the behavioural feedbacks in hazard assessment can alter the conclusions to the extent that they fail to identify maladaptive actions.

The sum of flood losses (Fig. 3) gives an estimate of what the ultimate outcome of different risk rationalities in societies would be. Risk monitoring societies adopt soft measures to face the flood risk, or relocate from floodplains with evident consequences for flood losses. On the other hand, the continued population growth of risk neglecting and risk downplaying societies, combined with a lack of policy informing flood memory that would lead to the adoption of hard or soft measures in the floodplain, comes at a clear cost: flood losses are substantially higher than for the other societies and will likely have a negative impact on the overall development of the respective society. A similar outcome can be seen when analysing the results for risk downplaying societies. Clearly, the reaction of risk monitoring societies stands out thus far, as participatory and inclusive measures increase preparedness, maintain memory and are built on the assumption that change in human behaviour may be necessary to decrease flood losses.

The risk controlling society strongly relies on building a levee system that increases in height from its original value as the water level of successive flood events increases. The model illustrates the economic cost but also the moral responsibility that is at stake in risk controlling societies through the "levee paradox": if the existence of a levee system, deemed safe by authorities, allows continued population growth to occur, the failure of these levees will have catastrophic consequences. Despite the sum of the flood losses not being substantially higher than for risk monitoring societies, the socio-hydrological model clearly illustrates the social product of risk, as this society, in an attempt to control risk, puts its population at high risk of large-scale flood events that would breach the levee system. In addition, this study provides evidence that levee systems will not yield the best possible results for flood losses over time.

As shown by Logan et al. (2018), neglecting future development and the temporal evolution of flood risk can result in incorrect conclusions being made regarding adaptation strategies. Comparing the adaptation strategies of the four societies in this study, the results show that the most substantial decrease in flood losses is linked to soft measures through, for example, citizen participation to increase awareness of flood risk and thus the society's capacity for preparedness. An egalitarian approach to flood risk is also contrary to the traditional top-down approaches. Moreover, it may reduce vulnerability through the equal participation of citizens, who may face structurally different vulnerability based on their status in the society. Therefore, the model illustrates that it is

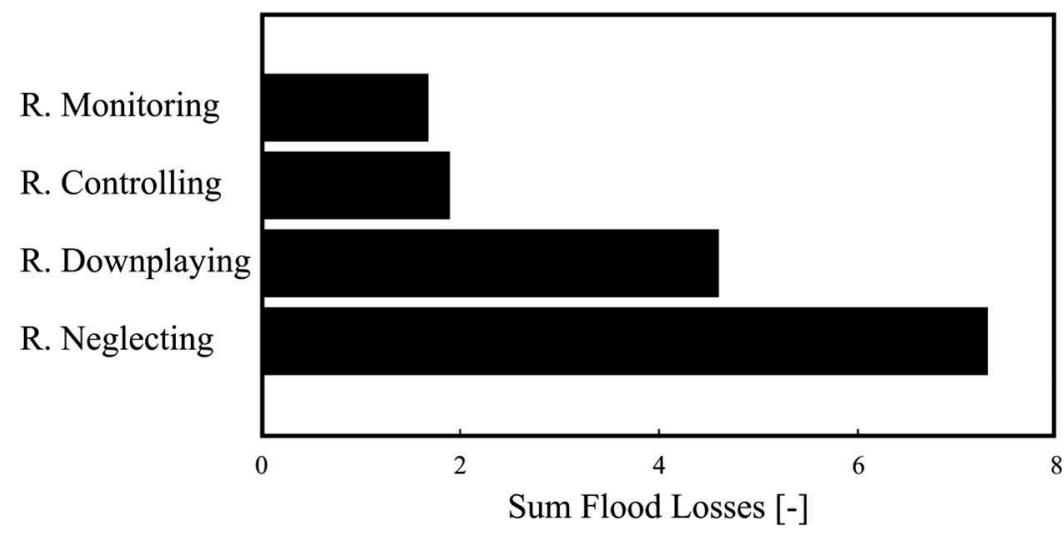

Figure 3. Sum of flood losses corresponding to the highest level of preparedness/awareness (i.e. highest $a_{D}$ value) for each society. 
of utmost importance to involve citizens with inclusive measures and increase their preparedness and responsiveness to flood events through, for instance, participative risk awareness programmes. In fact, increasing awareness through soft measures not only yields positive results, but yields better results than building a levee system. A forward-looking attitude that engages communities in risk monitoring behaviour is necessary and most suitable for building a more resilient environment and to minimize flood losses.

A caveat of this study is that the results are unavoidably affected by model assumptions, which simplify the connection between risk awareness and preparedness, while this relationship is more complex in the real world. The model also cannot account for other factors that may affect a society's decision to address flood risk, e.g. whether economic development of a settlement on a floodplain may hinder certain measures. Nevertheless, the use of ideal types of society allows scholars to predict the behaviour of societies facing hydrological risks. This type of prediction would be more difficult if one was dealing with non-ideal types of society.

\section{Conclusions}

In this paper, we integrated cultural theory and a socio-hydrological model to explore the dynamics of flood risk generated by the mutual feedback mechanisms between floods and four ideal types of society, formed by cultural risk rationalities. We distinguish between societies that neglect (fatalistic), control (hierarchical), downplay (individualist) or monitor (egalitarian) risk. Unsurprisingly, societies that tend to neglect existing risks, or are lulled into a false sense of safety by underestimating or downplaying risks, are in danger of experiencing high flood losses without the capacity to learn from past flood events and adopt adequate measures.

Societies that attempt to control flood risk through the construction of levees that are raised over time based on expert advice to adapt further will decrease their total flood losses substantially. However, the character of flood losses in these societies may have a dramatic impact on communities: a dense population in the floodplain that feels safe due to the presence of a levee may experience catastrophic outcomes of a flood event if the levee system fails. In contrast, risk monitoring societies stand out in their ability to maintain high flood-risk awareness and a memory of flood events that guides participatory preparedness measures. This type of society is shaped by soft measures, such as inclusive strategies or risk mitigation through resettling further from the floodplain. Consequently, the total flood losses are lower because of the combined effect of these adaptive, soft measures. Moreover, as the population adapts over time based on the experience of multiple, smaller flood events, our model does not identify any catastrophic impact of floods on this type of society, not even for water levels that cause catastrophic flood damage in other societies. This is a crucial result, as dramatic losses following floods may have a detrimental impact on the community's overall socioeconomic development, which may be halted due to large flood losses. These results imply that risk monitoring strategies through the adoption of soft measures may be more suitable to reduce flood losses over time and the only effective approach to prevent catastrophic flood events long-term.

Our modelling study has some caveats. In the real world, plural rationalities are also characterized by deep uncertainty (Churchman 1967), which is not accounted for in our modelling exercise. Moreover, as previously stated, different types of society correspond to ideal types of cultural rationalities. In the real world, multiple views and risk perceptions co-exist, influence each other and continuously change over time. However, it is important to emphasize that a study built on ideal types accepts that societies may not exist in their purest form in the real world for the sake of creating a framework that allows categorization and analysis with a much broader implication than, for example, the case study of one empirically existing type of society among many. Thus, by adapting Thompson et al.'s (1990) myths of nature and specifying a theoretical framework applicable to flood risk, this study makes a theoretical contribution to cultural theory, which can be further explored and developed in social sciences. Lastly, empirical evidence (Scolobig et al. 2012) suggests that the relationship between risk awareness and preparedness is more complex than that assumed in our model. Thus, we encourage future research to complement this theoretical work with more empirical research that specifically tests social science theories to advance the knowledge of how flood losses over time are influenced by different types of risk perception and to strengthen the integration of social sciences and hydrology.

\section{Acknowledgements}

The authors would like to acknowledge Anna Scolobig for fruitful discussions on an early version of this paper and the two anonymous reviewers whose comments helped to improve the paper.

\section{Disclosure statement}

No potential conflict of interest was reported by the authors.

\section{Funding}

This work was partly supported by the project HydroSocialExtremes Uncovering the Mutual Shaping of Hydrological Extremes and Society, Consolidator Grant (Project ID: 761678) by the European Research Council (ERC), H2020 Excellent Science, https://cordis.europa.eu/pro ject/rcn/214680/factsheet/en.

\section{ORCID}

E. Ridolfi (D) http://orcid.org/0000-0002-4714-2511

\section{References}

Ahmad, S. and Simonovic, S.P., 2000. System dynamics modeling of reservoir operations for flood management. Journal of Computing in Civil Engineering ASCE, 14 (3), 190-198. doi:10.1061/(ASCE)08873801(2000)14:3(190)

Bakarji, J., O’Malley, D., and Vesselinov, V.V., 2017. Agent-based socio-hydrological hybrid modeling for water resource management. Water Resources Management, 31, 3881. doi:10.1007/s11269-017-1713-7 
Barnett, J. and O'Neill, S., 2010. Maladaptation. Global Environmental Change, 20, 211-213. doi:10.1016/j.gloenvcha.2009.11.004

Berger, T., et al., 2007. Water Resources Management, 21, 129. doi: 10.1007/s11269-006-9045-Z

Blöschl, G., et al., 2019. Twenty-three unsolved problems in hydrology (UPH) - a community perspective. Hydrological Sciences Journal, 64 (10), 1141-1158. doi:10.1080/02626667.2019.1620507

Churchman, C., 1967. Guest editorial: wicked problems. Management Science, 14, 141-142.

Ciullo, A., et al., 2017. Socio-hydrological modelling of flood-risk dynamics: comparing the resilience of green and technological systems. Hydrological Sciences Journal, 62 (6), 880-891. doi:10.1080/ 02626667.2016.1273527

Da Deppo, L., Datei, C., and Salandin, S., 2004. Sistemazione dei Corsi D'acqua [in Italian]. Padova, Italy: Libreria Int. Cortina Padova.

Di Baldassarre, G., et al., 2010. Flood fatalities in Africa: from diagnosis to mitigation. Geophysical Research Letters, 37 (22), 2-6. doi:10.1029/ 2010GL045467

Di Baldassarre, G., et al., 2013a. Towards understanding the dynamic behaviour of floodplains as human-water systems. Hydrology and Earth System Sciences, 17, 3235-3244. doi:10.5194/hess-17-32352013

Di Baldassarre, G., et al., 2013b. Socio-hydrology: conceptualising human-flood interactions. Hydrology and Earth System Sciences, 17 (8), 3295-3303. doi:10.5194/hess-17-3295-2013

Di Baldassarre, G., et al., 2015. Debates-perspectives on socio-hydrology: capturing feedbacks between physical and social processes. Water Resources Research, 51, 4770-4781. doi:10.1002/2014WR016416

Di Baldassarre, G., et al., 2017. Drought and flood in the Anthropocene : feedback mechanisms in reservoir operation. Earth System Dynamics, 8, 225-233. doi:10.5194/esd-8-225-2017

Douglas, M. and Wildavsky, A., 1982. Risk and culture: an essay on the selection oftechnical and environmental dangers. Berkeley, CA: University of California Press.

Dryzek, J., 2013. The Politics of the Earth: environmental Discourses (Third Edit). New York, NY, USA: Oxford University Press.

$\mathrm{Du}, \mathrm{J}$., et al., 2012. Assessing the effects of urbanization on annual runoff and flood events using an integrated hydrological modeling system for Qinhuai River basin, China. Journal of Hydrology, 464, 127-139. doi:10.1016/j.jhydrol.2012.06.057

Elshafei, Y., et al., 2014. A prototype framework for models of socio-hydrology: identification of key feedback loops and parameterisation approach. Hydrology and Earth System Sciences, 18, 2141-2166. doi:10.5194/hess-18-2141-2014

Garde-Hansen, J., et al., 2017. Sustainable flood memory: remembering as resilience. Memory Studies, 10 (4), 384-405. doi:10.1177/17506980 16667453

Gohari, A., Mirchi, A., and Madani, K., 2017. Water Resources Management, 31, 1413-1434. doi:10.1007/s11269-017-1575-Z

Hanak, E., 2011. Managing California's water: from conflict to reconciliation. San Francisco, CA: Public Policy Institute of California.

Kundzewicz, Z.W. and Kaczmarek, Z., 2009. Coping with hydrological extremes. Water International, 25 (1), 66-75. doi:10.1080/025080600 08686798

Liu, Y., et al., 2014. Socio-hydrologic perspectives of the co-evolution of humans and water in the Tarim River basin, Western China: the Taijitire model. Hydrology and Earth System Sciences, 18, 1289-1303. doi:10.5194/hess-18-1289-2014

Logan, T.M., Guikema, S.D., and Bricker, J.D., 2018. Hard-adaptive measures can increase vulnerability to storm surge and tsunami hazards over time. Nature Sustainability, 1 (9), 526-530. doi:10.1038/s41893-018-0137-6
Loucks, D.P., 2015. Debates-perspectives on socio-hydrology: simulating hydrologic-human interactions. Water Resources Research, 51, 4789-4794. doi:10.1002/2015WR017002

Magnan, A.K., et al., 2016. Addressing the risk of maladaptation to climate change. WIREs Climate Change, 7, 646-665. doi:10.1002/wcc.409

Mård, J., Di Baldassarre, G., and Mazzoleni, M., 2018. Nighttime light data reveal how flood protection shapes human proximity to rivers. Science Advances, 4, 8. doi:10.1126/sciadv.aar5779

Montanari, A., et al., 2013. "Panta Rhei-everything Flows": change in hydrology and society-the IAHS Scientific Decade 2013-2022. Hydrological Sciences Journal, 58, 1256-1275. doi:10.1080/02626667. 2013.809088

Montesarchio, V., et al., 2014. Comparison of methodologies for flood rainfall thresholds estimation. Natural Hazards, 75 (1), 909-934. doi:10.1007/s11069-014-1357-3

Nardi, F., et al., 2019. GFPLAIN250m, a global high-resolution dataset of Earth's floodplains. Scientific Data, 6, doi: 10.1038/sdata.2018.309

Ostrom, E., 2000. Collective action and the evolution of social norms. Journal of Economics Perspectives, 14 (3), 137-158. doi:10.1257/jep.14.3.137

Penning-Rowsell, E.C., 1996. Flood-hazard response in Argentina. Geographical Review, 86 (1), 72-90. doi:10.2307/215142

Prosdocimi, I., Kjeldsen, T.R., and Miller, J.D., 2015. Detection and attribution of urbanization effect on flood extremes using nonstationary flood-frequency models. Water Resources Research, 51, 4244-4262. doi:10.1002/2015WR017065

Raaijmakers, R., Krywkow, J., and van der Veen, A., 2008. Flood risk perceptions and spatial multi-criteria analysis: an exploratory research for hazard mitigation. Natural Hazards, 46, 307. doi:10.1007/s11069-007-9189-z

Ridolfi, E., et al., 2013. Evaluation of rainfall thresholds through entropy: influence of bivariate distribution selection. Irrigation and Drainage, 62, S2. doi:10.1002/ird.1807

Scolobig, A., et al., 2017. Warning system options for landslide risk: a case study in upper Austria. Resources, 6 (3), 37. doi:10.3390/resources 6030037

Scolobig, A., De Marchi, B., and Borga, M., 2012. The missing link between flood risk awareness and preparedness: findings from case studies in an Alpine. Natural Hazards, 63, 499-520. doi:10.1007/ s11069-012-0161-1

Sivapalan, M., 2015. Debates-perspectives on socio-hydrology: changing water systems and the "tyranny of small problems"-socio-hydrology. Water Resources Research, 51 (6), 4795-4805. doi:10.1002/2015WR017080

Steg, L. and Sievers, I., 2000. Cultural theory of individual perceptions of environmental risks. Environment and Behavior, 32 (2), 248-267. doi: $10.1177 / 00139160021972513$

Suriya, S. and Mudgal, B.V., 2012. Impact of urbanization on flooding: the Thirusoolam sub watershed - A case study. Journal of Hydrology, 412, 210-219. doi:10.1016/j.jhydrol.2011.05.008

Thompson, M., Ellis, R., and Wildavsky, A., 1990. Cultural theory. Boulder, CO: Westview Press.

Tierney, K., 2014. The social roots of risk: producing disasters, promoting resilience. Stanford, CA: Stanford University Press.

Ullberg, S.B., 2018. Forgetting flooding?: post-disaster livelihood and embedded remembrance in Suburban Santa Fe, Argentina. Nature and Culture, 13, 27-45.

Viglione, A., et al., 2016. Attribution of regional flood changes based on scaling fingerprints. Water Resources Research, 52, 5322-5340. doi:10.1002/2016WR019036

Watkins, J.W.N., 1952. Ideal types and historical explanation. The British Journal for the Philosophy of Science, 3 (9), 22-43. doi:10.1093/bjps/III.9.22

White, G.F. (1945). Human adjustments to floods. research paper no. 29, Department of Geography Research, Chicago University, USA. 